\title{
Detection of ischaemic heart disease with risk factors in different cate- gories of employees of University Grants Commission
}

\author{
Syed Ali Ahsan 1 , K.M.H.S. Sirajul Haque ${ }^{1}$, Mohammad Salman ${ }^{1}$ \\ Ahmed Saiful Bari1 ${ }^{1}$, Habiba Nahar ${ }^{1}$, Md. Khurshed Ahmed ${ }^{1}$, Md. Harisul Hoque ${ }^{1}$, Md. Mukhlesur Rahman ${ }^{1}$ \\ Md. Aslam Hossain², Md. Ashraf Uddin Sultan ${ }^{1}$ \\ ${ }^{1}$ Department of Cardiology, Bangabandhu Sheikh Mujib Medical University, Dhaka \\ ${ }^{2}$ Department of Cardiac Surgery, Bangabandhu Sheikh Mujib Medical University, Dhaka
}

\author{
Address for correspondence \\ Dr. Syed Ali Ahsan, Associate Professor, Department of Cardiology, Bangabandhu Sheikh Mujib Medical University, Dhaka. \\ E-mail : draliahsam@yahoo.com
}

\begin{abstract}
Coronary artery disease is the major cause of mortality world wide. The potentially modifiable risk factors for coronary artery disease were increased concentrations of low density lipoprotein cholesterol, decreased concentrations of high density lipoprotein cholesterol, hypertension, hyperglycemia, and smoking.This cross sectional study which included all UGC employees was conducted in the department of cardiology of BSMMU between January 2007 and December 2007. Detailed clinical history, family history, lifestyle, smoking habit, diabetes mellitus, and hypertension, regular use of any medication or any previous cardiac intervention was taken. Physical examination, Blood pressure measurement, ECG, Echocardiography, fasting blood sugar and fasting lipid profile was done to all subjects.163 subjects (all UGC employees), mean age 44.8 \pm 8.3 years were included in this study. (20.9\%) presented with angina pectoris, $3.7 \%$ were having palpitation, and $8.6 \%$ were having shortness of breath and $5.5 \%$ with nonspecific chest pain. $16.6 \%$ subjects presented with hypertension, $12.3 \%$ with diabetes mellitus, and $20.9 \%$ with dyslipidemia. $3.1 \%$ subjects had previous myocardial infarction. ECG shows $8.0 \%$ subjects had inferior ischemia, $6.1 \%$ had anterior ischemia and 2.5\% had bundle branch block. Echocardiography shows $4.9 \%$ subjects were having regional wall motion abnormalities Prevalence of risk factors for CAD is increasing, and with the clinical and cost burdens mounting, identifying and treating those at risk remains a national priority.
\end{abstract}

Abbreviations UGC, University Grants Commission, BSMMU, Bangabandhu Sheikh Mujib Medical University.

\section{Introduction}

Atherosclerosis leading to coronary heart disease is complex in origin. Involved in the pathogenesis of atherosclerosis are hemodynamic, thrombotic, and carbohydrate-lipid metabolic variables, along with intrinsic characteristics of the arterial wall ${ }^{1}$. These physiologic and biochemical factors underlie the clinical events that may eventually occur. Environmental factors such as smoking or a sedentary lifestyle also contribute to this process. The progression of atherosclerotic disease and the increasing severity of atherosclerosis relate not only to the presence and extent of cardiovascular risk factors but also to the persistence of risk factors over time 2 , 3. Sudden death may occur in a young person with only a single lesion complicated by a coronary thrombus, without extensive vessel disease. Consequently, the extent of vascular lesions may not be directly related to the occurrence of clinical events, such as myocardial infarction. Morbidity due to coronary artery disease, however, is generally related to the extent of vascular lesions ${ }^{4}$. In this regard, clinical risk factors are considered to be useful in predicting the severity of atherosclerosis 5 .

Epidemiologic studies have established that multiple risk factors increase the probability of cardiovascular events, since cardiovascular risk factors tend to reinforce each other in their influence on morbidity and mortality ${ }^{6}$. Although a specific risk factor influences the risk that a person will have cardiovascular disease, risk factors tend to aggregate and usually appear in combination.

The past decade has witnessed major strides in the prevention of coronary artery disease (CAD) through modification of its causes. The most dramatic advance has been the demonstration that aggressive medical therapy will substantially reduce the likelihood of recurrent major coronary syndromes in patients with established CAD (secondary prevention). A similar potential exists for risk reduction in patients without established CAD (primary prevention). 7

In this survey we tried to find out of presence of risk factors of coronary artery disease among the University grants commission (UGC) employees. Coronary angiography is the invasive tool to assess the atherosclerotic burden but it is not feasible in asymptomatic patients. So we tried to do the indirect assessment of the coronary atherosclerosis in UGC employees by assessing the coronary risk factors in all age group. 


\section{Methods}

This study was conducted in the department of Cardiology BSMMU. In this cross sectional survey, UGC employees were enrolled between January 2007 and December 2007. After taking informed consent a detailed history regarding cardiac symptoms such as chest discomfort on exertion, family history of cardiovascular disease, lifestyle whether sedentary or active, smoking habit, diabetes mellitus, hypertension, regular use of any medication or any previous cardiac intervention was taken. Sedentary life style was defined as any activity less 30 minutes of moderate intensity (brisk walking, gardening) if not all but most of the days of the week. ${ }^{8}$ Blood pressure was measured in right arm and an average of two readings taken 5 minutes apart was considered the blood pressure of the subject. Systolic blood pressure more than $140 \mathrm{~mm} \mathrm{Hg}$ and diastolic blood pressure more than 90 $\mathrm{mm} \mathrm{Hg}$ was taken as hypertension. Fasting blood sugar more than $7 \mathrm{~m} . \mathrm{mol} / \mathrm{l}$ was taken as diabetes mellitus. Dyslipidemia was defined as elevation of the serum total cholesterol, low-density lipoprotein (LDL) cholesterol and triglyceride (TG) concentrations, and a decrease in the highdensity lipoprotein (HDL) cholesterol concentration or the patient is taking lipid lowering drugs. Electrocar diography (ECG) and echocardiography (2D and M mode) was done in all subjects. Fasting blood glucose and fasting lipid profile was done by standardized procedure in the biochemistry laboratory of BSMMU.

\section{Statistical analysis}

Statistical analysis was done by SPSS (Statistical package for social sciences) version 12 for Windows. All the data were expressed as mean, standard deviation, number and percent as appropriate.

\section{Results}

163 subjects (UGC employees) enrolled between January 2007 and December 2007 was included in this study. Age of the subjects was Mean \pm SD $(44.8 \pm 8.3)$ years. $149(91.4 \%)$ subjects were male and $14(8.6 \%)$ were female.

Table I: Basic characteristics of the subjects $(\mathrm{N}=163)$

\begin{tabular}{|c|c|c|}
\hline Symptoms & 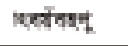 & terecutage \\
\hline Stalkle angina & 34 & 20.9 \\
\hline Palpitation & 6 & 3.7 \\
\hline Shortmess of bruath & $1+$ & 8.6 \\
\hline Non specific chest pain & 9 & 5.5 \\
\hline No Complaint & 100 & 613 \\
\hline
\end{tabular}

Results were expressed in Mean $\pm \mathrm{SD}$ and percent as appropriate.

$68(41.7 \%)$ subjects were in the age group of $31-40$ years, $37(22.7 \%)$ were in the age group of $41-50$ years and 58 $(35.6 \%)$ were in the age group of 51-60 years.
Table II: Clinical presentation of the subjects

\begin{tabular}{|c|c|c|c|c|c|}
\hline Varhables & Frequency & Percentage & Mean \pm SD & Minimum & Maximum \\
\hline $\begin{array}{c}\text { Age } \\
\text { (in years) }\end{array}$ & 163 & & $44.8 \pm 8.3$ & 31 & 60 \\
\hline Male & 149 & 91.4 & & & \\
\hline Female & 14 & 8.6 & & & \\
\hline
\end{tabular}

Results were expressed in number and percent.

$34(20.9 \%)$ were presented with angina pectoris, $6(3.7 \%)$ were having palpitation, $14(8.6 \%)$ were having shortness of breath, $9(5.5 \%)$ were presented with nonspecific chest pain where as $100(61.3 \%)$ subjects were having no complaints.

Pie chart showing the smoking habit among the UGC employees

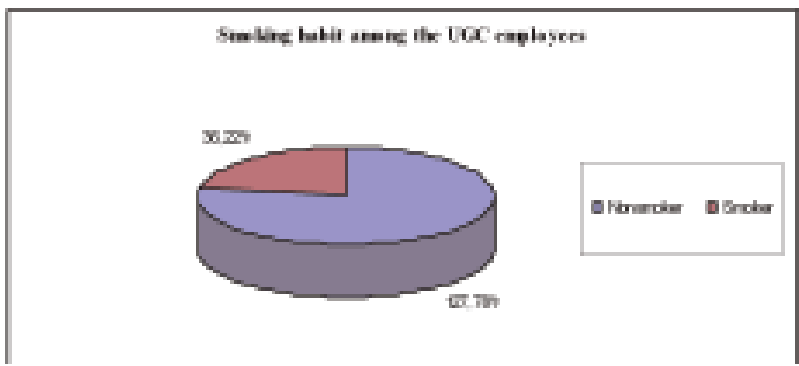

Pie chart showing the smoking habit among the UGC employees. $36(22 \%)$ of the subjects were the smokers.

Table III: Frequency of different clinical conditions detected in UGC employees $(\mathrm{N}=163)$

\begin{tabular}{ccc}
\hline Variables & Frequency & Percentage \\
\hline Hypertension & 27 & 16.6 \\
Diabetes mellitus & 20 & 12.3 \\
Dyslipidemia & 34 & 20.9 \\
Myocardial infarction & 5 & 3.1 \\
\hline
\end{tabular}

Results were expressed in number and percent.

We found, 27 (16.6\%) subjects were having hypertension, $20(12.3 \%)$ were having diabetes mellitus, 34 (20.9\%) having dyslipidemia. 5 (3.1\%) subject were detected with previous myocardial infarction.

Table IV: Lipid parameters in subjects with and with out dyslipidemia

\begin{tabular}{|c|c|c|}
\hline Lipid parameters & $\begin{array}{l}\text { Subjects with oett } \\
\text { dyslipidemiaa } \\
\text { (Mean_SD) }\end{array}$ & $\begin{array}{l}\text { Subjects with } \\
\text { dyslipidemia } \\
\text { (MeanıSD) }\end{array}$ \\
\hline Total cholesterol & $164 \pm 37,9$ & $190+38.6$ \\
\hline Triglyeeride & $142.6 \pm 60.1$ & $171 \pm 69.2$ \\
\hline High density & $43.7 \pm 3.4$ & $33.9+3.6$ \\
\hline lipoprotcin (HDL) & & \\
\hline $\begin{array}{l}\text { Low density } \\
\text { lipogrotein (L.DL). }\end{array}$ & $895 \pm 35,6$ & 12139.5 \\
\hline
\end{tabular}

All the date expressed in mean and standard deviation.

Table IV shows that all lipid parameters were higher in the subjects with dyslipidemia. 
Table V: Electrocardiography findings of the UGC employees $(\mathrm{N}=163)$

\begin{tabular}{ccc}
\hline ECG findings & Frequency & Percentage \\
\hline Inferior ischemia & 13 & 8.0 \\
Anterior ischemia & 10 & 6.1 \\
Myocardial infarction & 5 & 3.1 \\
Bundle branch block: & 4 & 2.5 \\
Normal & 131 & 80.4 \\
\hline
\end{tabular}

Results were expressed in number and percent.

In this study we found $13(8.0 \%)$ subjects were having inferior ischemia, 10 (6.1\%) were having anterior ischemia, 4 $(2.5 \%)$ were having bundle branch block whereas $131(80.4 \%)$ were found with normal ECG.

Table VI: Echocardiographic findings of the UGC employees $(\mathrm{N}=163)$

\begin{tabular}{ccc}
\hline Echocardiographic findings & Frequency & Percentage \\
\hline Regional wall motion & 8 & 4.9 \\
atmormalities (RWMA) & 7 & 4.3 \\
Septal hopertrophy & 7.3 & 90.8 \\
nonmal & 148
\end{tabular}

Results were expressed in number and percent.

8 (4.9\%) subjects were having regional wall motion abnormalities, 7 (4.3\%) were having septal hypertrophy and 148 $(90.8 \%)$ were found with normal echocardiography findings.

Table VII: Different class of drugs used by UGC employees $(\mathrm{N}=\mathbf{1 6 3})$

\begin{tabular}{|c|c|c|}
\hline Name of the drug & Frequeac? & Percentage \\
\hline $\begin{array}{l}\text { Angiotensin converting enrywe } \\
\text { inkilovos (ACF) }\end{array}$ & 8 & 4.9 \\
\hline Beta blockir & 18 & 11.0 \\
\hline Calcium channd blocker ( $\mathrm{CCB}$ ) & 7 & 4.3 \\
\hline Oral bxpoglvcervic drugs & 14 & 8.6 \\
\hline lnaulin & 3 & 1.8 \\
\hline No drag used & 113 & 69,3 \\
\hline
\end{tabular}

Results were expressed in number and percent.

In this study 8 (4.9\%) subjects were using ACE inhibitor, 18 $(11 \%)$ were using beta blockers and $7(4.3 \%)$ were on calcium channel blockers. We found $14(8.6 \%)$ were on oral hypoglycemic drugs and $3(1.8 \%)$ were getting insulin. 113 $(69.3 \%)$ were not using any medication.

\section{Discussion}

CAD is the leading cause of death in all World Bank developing regions, with the exception of sub-Saharan Africa9.The major and independent risk factors for coronary artery (CAD) are cigarette smoking of any amount, elevated blood pressure, elevated serum total cholesterol and lowdensity lipoprotein cholesterol (LDL-C), low serum highdensity lipoprotein cholesterol (HDL-C), diabetes mellitus, and advancing age. The quantitative relationship between these risk factors and CAD risk has been elucidated by the Framingham Heart Study 7 . UGC employees are mostly sedentary workers. Modifiable risk factors like smoking were common in them. There are more than one billion smokers worldwide, and 80 percent of them reside in developing countries..$^{10}$ Nearly one-third of all tobacco users in the developing world die from CAD. ${ }^{10}$ Most of the subjects in this survey were male and male sex is more prone to develop coronary artery disease. In this study we found a considerable proportion of the subjects were having angina pectoris. In accord, the recent Framingham report7 also provided estimates for "hard" CAD, excluding angina pectoris. The inclusion of coronary insufficiency (unstable angina) and unrecognized myocardial infarction (defined by electrocardiography) probably gives estimates of hard CAD that are somewhat higher than combined end points reported in several clinical trials. ${ }^{11,12,13,14}$

In this survey we found large proportion is having hypertension, dyslipidaemia and diabetes mellitus. Diabetes mellitus is a major risk factor for CAD is well established. ${ }^{7}$ Both type 1 diabetes ${ }^{15}$ and type 2 diabetes ${ }^{16}$ confer a heightened risk for CAD. Type 2 diabetes is of particular concern because it is so common and usually occurs in persons of advancing age, when multiple other risk factors coexist. There is a growing consensus that most patients with diabetes mellitus, especially those with type 2 diabetes, belong in a category of high short-term risk. When the risk factors of diabetic patients are summed, their risk often approaches that of patients with established CAD. ${ }^{17}$ Dyslipidaemia is a recognized risk factor for CAD. In this survey we included dyslipidaemia rather than low HDL-C and high LDL-C as in some report hypertriglyceridemia is correlated with other risk factors $^{18}$; however, its degree of independent predictive power is difficult to assess. Several clinical trials ${ }^{19,209,21}$ found that drugs that primarily affect triglyceride-rich lipoproteins reduce CAD risk when used with patients with hypertriglyceridemia. Elevated triglycerides consequently may become a target of therapy independent of LDL-C lowering. In this survey we found $3 \%$ subjects were having myocardial infarction in this group secondary prevention for $\mathrm{CAD}$ is mandatory. The highest groups at risk for death among initial survivors of AMI are those with congestive heart failure (CHF). The prognosis for those with established CHF is generally poor and worse than for most malignancies or AIDS, with a five-year mortality of 26-75 percent overall and oneyear mortality rate as high as 40 percent for those at the most advanced stage. ${ }^{22}$

Four generic medicines - aspirin, beta-blockers, cholesterol reducers (in particular, statins), and ACE inhibitors - have been the mainstay of treatment for those with coronary heart disease in the developed world. A combination of aspirin and atenolol was cost saving when compared to no therapy in all developing regions. 


\section{Conclusion}

A global CAD epidemic is rapidly evolving, and the burden of disease is shifting. Three times as many deaths from CAD now occur in developing countries as compared with developed countries. ${ }^{23}$ The economic and social costs of this burden will be great, particularly because many developing nations are still grappling with poverty-related diseases such as malnutrition, infectious diseases, and poor health care facilities. However, a broad range of individual- and population-based strategies exists at affordable prices and, if implemented, could reduce the burden of CAD disease by more than half. Reductions in tobacco use should be the cornerstone of these interventions. Simultaneously, efforts can be adopted to prevent the further development of CAD risk factors. This survey was done in a small group of UGC employees but it reflected the image of CAD in the society. It is a challenge to our intellect and enterprise to apply our knowledge creatively and cost-effectively to minimize the burden of cardiovascular disease.

\section{References}

1. Ross R. The pathogenesis of atherosclerosis: a perspective for the 1990s. Nature1993; 362:801-09.

2. Dawber TR. The Framingham Study: the epidemiology of atherosclerotic disease. Cambridge, Mass.: Harvard University Press, 1980.

3. Stamler J, Dyer AR, Shekelle RB, Neaton J, Stamler R. Relationship of baseline major risk factors to coronary and allcause mortality, and to longevity: findings from long-term follow-up of Chicago cohorts. Cardiology 1993;82:191-222.

4. Roberts WC. Qualitative and quantitative comparison of amounts of narrowing by atherosclerotic plaques in the major epicardial coronary arteries at necropsy in sudden coronary death, transmural acute myocardial infarction, transmural healed myocardial infarction and unstable angina pectoris. Am J Cardiol 1989; 64:324-28

5. Solberg LA, Strong JP. Risk factors and atherosclerotic lesions: a review of autopsy studies. Arteriosclerosis 1983; 3:187-98.

6. Kannel WB, Wolf PA, Garrison RJ. The Framingham Study: an epidemiological investigation of cardiovascular disease. Bethesda, Md.: National Heart, Lung, and Blood Institute, 1987. (NIH publication no. 87-2703.)

7. Wilson PW, D'Agostino RB, Levy D, Belanger AM, Silbershatz H, Kannel WB. Prediction of coronary heart disease using risk factor categories. Circulation. 1998;97:1837-47.

8. Powell KE, P D Thompson PD, Caspersen CJ, and, Kendrick JS. Physical Activity and the Incidence of Coronary Heart Disease Annu Rev Public Health, 1987 ;8: 253-87

9. C.D. Mathers et al., "Deaths and Disease Burden by Cause: Global Burden of Disease Estimates for 2001 by World Bank
Country Groups," Disease Control Priorities Project Working Paper no. 18 (Bethesda, Md.: Fogarty International Center, National Institutes of Health, 2001).

10. Jha et al., "Tobacco Addiction," in Disease Control Priorities, ed. Jamison et al., 869-886.

11. Randomised trial of cholesterol lowering in 4444 patients with coronary heart disease:the Scandinavian Simvastatin Survival Study (4S). Lancet. 1994; 344: 1383-89

12. Shepherd J, Cobbe SM, Ford I, Isles CG, Lorimer AR, MacFarlane PW, McKillop JH, Packard CJ. Prevention of coronary heart disease with pravastatin in men with hypercholesterolemia: West of Scotland Coronary Prevention Study Group. N Engl J Med.. 1995; 333: 1301-07.

13. Sacks FM, Pfeffer MA, Moye LA, Rouleau JL, Rutherford JD, Cole TG, Brown L, Warnica JW, Arnold JM, Wun CC, Davis BR, Braunwald E. The effect of pravastatin on coronary events after myocardial infarction in patients with average cholesterol levels: Cholesterol And Recurrent Events Trial Investigators. N Engl J Med. 1996;335:1001-09.

14. The Long-term Intervention with Pravastatin in Ischaemic Disease (LIPID) Study Group. Prevention of cardiovascular events and death with pravastatin in patients with coronary heart disease and a broad range of initial cholesterol levels. N Engl J Med. 1998; 339: 1349-57.

15. Lloyd CE, Kuller LH, Ellis D, Becker DJ, Wing RR, Orchard TJ. Coronary artery disease in IDDM: gender differences in risk factors but not risk. Arterioscler Thromb Vasc Biol. 1996; 16:720-26.

16. Wilson PW. Diabetes mellitus and coronary heart disease. Am J Kidney Dis. 1998; 32:89-100.

17. Haffner SM, Lehto S, Ronnemaa T, Pyorala K, Laakso M. Mortality from coronary heart disease in subjects with type 2 diabetes and in nondiabetic subjects with and without prior myocardial infarction. N Engl J Med. 1998; 339:229-34.

18. Grundy SM. Hypertriglyceridemia, atherogenic dyslipidemia, and the metabolic syndrome. Am J Cardiol. 1998;81:18-25.

19. Manninen V, Huttunen JK, Heinonen OP, Tenkanen L, Frick $\mathrm{MH}$. Relation between baseline lipid and lipoprotein values and the incidence of coronary heart disease in the Helsinki Heart Study. Am J Cardiol. 1989;63:42-7.

20. Carlson LA, Rosenhamer G. Reduction of mortality in the Stockholm ischaemic heart disease secondary prevention study to combined treatment with clofibrate and nicotinic acid. Acta Med Scand. 1988;223:405-18.

21. Kaplinsky E. The Bezabifrate Infarction Prevention Study. Paper presented at: Annual Meeting of the European Society of Cardiology; August 1998; Vienna, Austria.

22. McMurray JJ, Stewart S. "Epidemiology, Aetiology, and Prognosis of Heart Failure," Heart 2000; 83; 5: 596-602.

23. Beaglehole R, World Health Report 2003: Shaping the Future (Geneva: WHO, 2003). 